\title{
1. Introduction: from governance to entrepreneurial consumers
}

This book is about content, technology, globalization and the challenges faced by creative and cultural businesses in a digital age. It deals in part with the tension between state-generated frameworks for managing creative industries and the changing mental technology that citizens carry with them in a rapidly evolving digital world. Most importantly, it examines the shift from statecontrolled cultural production and consumption towards the emergence of 'entrepreneurial consumers' in China and considers what this might mean for the way that innovation, knowledge production and sources of growth are understood in the creative and cultural industries in the twenty-first century.

In the People's Republic of China (PRC), social, economic, political and technological transformations are having a powerful impact on the context within which creative and cultural activities occur. Although China remains a single-party state, the shift towards a market-driven economic system means that it is no longer possible for the government to dominate popular culture with the level of effectiveness witnessed under Mao. Economic reform has generated new space for market-driven activity, legal reforms have created new classes of property rights in creative and cultural works and brand identities, and digital technologies are transforming processes of production, distribution and delivery.

Systems that were once effective at controlling the ways in which popular culture was made and used are being challenged by an explosion in unauthorized distribution channels, as well as by the growing capacity of consumers to make their own content and to use existing material for new purposes. A market-driven economy, increased availability of information about cultural products and trends, new technologies and growing disposable incomes are all providing China's citizens with opportunities to understand consumption as a game with social costs and benefits: money, risk, status, fun and power. In navigating this new landscape, consumers are developing the skills and habits of entrepreneurs - with profound consequences for creative and cultural businesses.

In this book the shift away from centralized control of creativity and cultural production by the state towards much more dynamic models of creative consumption is traced through three of China's newly defined creative 
industries: film, music and fashion. Film, music and fashion have been chosen because there are important differences in the ways in which state, corporate and consumer power are interacting in each of these industries. Businesses in all three areas are developing unique strategies for navigating changes in government regulation, as well as new commercial opportunities associated with cultural and economic reform. The impact of new technologies on business models and the extent to which consumers are able to influence creative production and decide how products are used and experienced also varies across these three sectors.

Revolutionary songs, operas and films have all been considered central to the Communist Party of China's (CPC) efforts to win the hearts and minds of the people, to imbue China's population with revolutionary fervour, and to convey political, ideological and moral messages to society (Kraus 2004). Fashion, too, has served political and ideological ends under the CPC: the body is a powerful site for disciplining the mind and the outward display of support for and conformity with the ideological goals of the state (Hooper 1994: 164). But, while film, music and fashion have all been associated with the exercise of state power over individuals at various times since 1949, the impact of economic reform and technological change on the growing business of culture in each of these industries has not been uniform.

I suggest that the film industry might be understood as an example of continuing state agency in the realm of cultural production. It must be said straight away that the reality of consumption in a country where unauthorized copying and distribution networks are so well developed is a different matter. By contrast, the role of entrepreneurial commercial classes is becoming increasingly obvious in the development of profit-focused elements of China's music industry, particularly in relation to mobile distribution opportunities. Finally, fashion and the fashion industry in China rely most heavily on the active involvement of consumers in the productive process. The status-driven dynamics of fashion consumption and the fashion system's ability to accommodate consumer co-creation and entrepreneurship are making it possible for China's fashion industry to develop in the absence of a strong intellectual property system. As China is becoming more deeply integrated into a global fashion landscape, the business models that are being taken up by China's fashion industry are taking on the characteristics of those seen elsewhere in the world, including consumer entrepreneurship as a driver of innovation.

Since the Open Door Policy of the early 1980s, the government's efforts to control the distribution and consumption of films have been seriously undermined by unauthorized distribution of cinematic content. At first this occurred mainly via VHS cassettes, which were copied and circulated between networks of friends and associates. Throughout the 1990s and the first half of the 2000s, increasing integration into international communities of trade, 
growing disposable incomes and the growing availability of new technologies for copying, distribution and consumption were associated with the growth of highly sophisticated networks for the sale of illegally copied cinematic works, prompting international calls for the Chinese government to clamp down on film 'piracy' and to increase access to the Chinese market for international copyright owners.

By early 2009 it was becoming harder to find shops selling 'pirated' DVDs on the streets of Beijing and Shanghai. To a casual observer it might appear that international pressure for better enforcement of copyright is beginning to have an impact on local practices. However, the declining visibility of 'pirated' DVDs is coinciding with technological changes that provide cheaper, more convenient means of accessing content for many urban consumers. By June 2009 China was home to 338 million internet users, 320 million of whom had broadband access (CNNIC 2009), and low levels of copyright enforcement online are making it possible for ever-increasing numbers of people either to stream or to download a very wide range of content through search engine links and dedicated film streaming sites, without leaving the comfort of their desks.

But, in spite of the rapid expansion of unauthorized distribution networks that has occurred in China over the past 30 years, the commercially focused film industry continues to be dominated by censorship policies and other government-administered structures of control. High costs associated with making commercially competitive films, the continued existence of pre- and post-production film censorship, and government control over cinema-based exhibition are preventing the film industry from breaking away from state influence. Cultural policies remain a defining feature and are limiting the spaces in which commercially focused film industry entrepreneurs can operate.

In certain areas of the music industry, on the other hand, lower production costs and less restrictive cultural policies are allowing greater space for a commercially focused entrepreneurial class to operate. Some Chinese entrepreneurs have been quick to understand music's potential to generate financial returns, as well as the commercial power associated with controlled distribution channels, such as mobile phone networks. Overall, there appears to be greater opportunity for an entrepreneurial class to have an impact on the music industry's development than in the case of the film industry.

The groups that are emerging as most powerful in terms of their ability to act as gatekeepers to lucrative distribution networks and commercial opportunities in China appear not to be the major record labels that so successfully established dominant positions within the commercial music industry in other markets. Rather, mobile phone operators and, to a certain extent, search engines are playing a powerful role in this emerging commercial landscape, 
challenging common Western notions of the way in which a recorded music industry functions.

In Western markets, common recording industry business models rely on communities of hopeful amateurs as an important source of 'talent'. Entrepreneurs and entrepreneurial firms (record labels) invest in development, production, promotion and distribution of the works of carefully selected artists, in return for the assignment of intellectual property and contractual rights. The assignment of these rights allows labels to recoup costs and generate profits from the sale of physical music products, as well as licensing on works in their accumulated repertoire. While new technologies for distribution and consumption of music are challenging this business model, even in the markets in which it has been most firmly established, such as the United States and Western Europe, labels continue to play an important role as brokers of new talent and coordinators of supply.

However, in China record labels have struggled to construct a similar role for themselves. Very high rates of unauthorized copying and distribution of physical media and difficulties associated with enforcing intellectual property rights online have prevented a record-label-centred model from taking hold. It appears that mobile operators and search engines, rather than labels, are dominant forces in the distribution of music in China, at least for now. But the role of music industry executives has not disappeared entirely, and the structure of the music industry, as an emerging area of economic activity, remains in flux. Although copyright is difficult to enforce, it is beginning to play a role in the negotiation of distribution rights. Furthermore, Chinese record labels and executives play an additional role to their counterparts in the West: negotiating government content regulations and ensuring that music and public performance comply with censorship policies.

In a market-driven economy that provides access to an unprecedented array of content, technology, products, services and experiences, the impact of consumer decisions on cultural production has increased. In some ways, this is a predictable outcome of market reforms in the cultural sector. However, transformative technologies have added new elements to the well-rehearsed story of supply and demand. The internet, high-powered personal computers, mobile devices and an increasingly lucrative services sector are changing relationships between 'producers' and 'consumers' of cultural products. It is becoming harder and more expensive to maintain control over distribution and reuse. Instant communication is increasing the power of social networks, allowing 'consumers' to apply creativity and skills to generate content and value, and to draw on information provided by trusted friends or communities in order to supplement that which is supplied by either the state or commercially interested advertisers.

Many of China's consumers are experimenting with different ways of inter- 
acting with creative works. It has become possible to 'play' with content in ever more personal ways, to use it to connect with others, to create an image of oneself, to strengthen social connections or to build social capital. Music can be 'displayed' to others as a mobile ring tone, personalized ring-back tone or web-page wallpaper. It can also be composed, mashed or remixed, and then shared with friends and online communities, who might enjoy it, pass it on or change it. Digital cameras, mobile phones and photo-sharing sites on the internet make it possible for people to tell stories about themselves and their world in new ways and are encouraging innovative forms of creative experimentation, collaboration and activism.

Technological developments that are making new kinds of creativity, interaction and distribution possible do not mean that existing structures for the production and distribution of creative and cultural works no longer have a role to play. However, disruptive technologies that make it possible for consumers in China and elsewhere in the world to access, use and distribute content and information in new ways raise a number of important questions about how value is generated in the creative industries. Do uncontrolled copying and peer-to-peer distribution prevent commercial development in the creative industries? Does an inability to enforce intellectual property rights remove incentives for investment in creativity and innovation? If so, is a strong intellectual property system a prerequisite for the growth of the creative industries? How might understanding this process better inform approaches to the protection of intellectual property in the context of digital technologies and global content flows, where controlling copying and distribution is more difficult than ever before?

One area that might provide some insight into changing dynamics of production, distribution and consumption in a digital age is fashion. Rather than being threatened by copying - of styles, looks and designs - innovation in the fashion industry is driven forward by these activities as consumers search for status and novelty and designers and retailers seek out new ways to provide it. Because status and identity are driving forces in the fashion industry, consumers are active participants in processes that create commercial value. The choices of lead consumers help to popularize new trends, information about choices is shared through social networks ('I love your hat - where did you get it?') and innovations made by consumers in the form of street fashion help to provide inspiration for design professionals.

Creative remixing is integral to processes of both fashion production and consumption, occurring when consumers attempt to imitate a 'look' or chose a flattering ensemble, or when designers scour vintage shops, art exhibitions or fashion magazines in search of inspiration for the next season's collection. The fashion system's dependence on creative remixing means that high levels of semiotic literacy are rewarded among both fashion professionals and 
consumers, who must understand the symbolic value of the elements that they are recombining in order to minimize the risk involved in their choices and to maximize the chances that their innovations will be admired and convey a desired message.

Fashion involves risks and benefits: rewarding consumers who become literate in the complex language and rules of the system and punishing those who deviate too far from accepted norms or make the 'wrong' choices. It encourages consumers to engage in thoughtful experimentation and to critically consider new trends in the context of their own tastes, preferences, values and desired associations. Because fashion provides consumers with opportunities for individual creativity, self-expression and innovation, the fashion industry is one in which 'consumers' are anything but passive. Rather, the fashion system demands that they are actively involved in a process of productive consumption.

Table 1.1 The value chain of three different creative industries in China, showing the shift from top-down control to bottom-up productivity

\begin{tabular}{|c|c|c|c|}
\hline & Film & Music & Fashion \\
\hline Production & $\begin{array}{l}\text { High capital } \\
\text { requirements. }\end{array}$ & $\begin{array}{l}\text { Lower capital } \\
\text { requirements. } \\
\text { Diverse sources } \\
\text { of production. }\end{array}$ & $\begin{array}{l}\text { Distributed creative } \\
\text { production. } \\
\text { Consumer } \\
\text { involvement in } \\
\text { creative iteration is } \\
\text { encouraged. }\end{array}$ \\
\hline Distribution & $\begin{array}{l}\text { State control of } \\
\text { access to } \\
\text { commercially } \\
\text { significant } \\
\text { distribution } \\
\text { channels. }\end{array}$ & $\begin{array}{l}\text { State dominance } \\
\text { over commercially } \\
\text { significant } \\
\text { distribution } \\
\text { channels. }\end{array}$ & $\begin{array}{l}\text { Distribution is } \\
\text { managed by the } \\
\text { market. }\end{array}$ \\
\hline Regulation & $\begin{array}{l}\text { Commercial } \\
\text { opportunities } \\
\text { heavily dependent } \\
\text { on spaces defined } \\
\text { by the state. } \\
\text { Pre- and post- } \\
\text { production } \\
\text { censorship. }\end{array}$ & $\begin{array}{l}\text { Distribution licensing } \\
\text { at the discretion of } \\
\text { authorized publishers. } \\
\text { Licensing for large } \\
\text {-scale public } \\
\text { performances. } \\
\text { Centralized } \\
\text { censorship processes } \\
\text { for international } \\
\text { artists. }\end{array}$ & $\begin{array}{l}\text { Policies focused on } \\
\text { creating an } \\
\text { environment } \\
\text { conducive to the } \\
\text { growth of a fashion } \\
\text { industry, rather than } \\
\text { direct control. }\end{array}$ \\
\hline Consumption & Passive.* & Interactive. & $\begin{array}{l}\text { Participatory, } \\
\text { entrepreneurial, } \\
\text { productive. }\end{array}$ \\
\hline
\end{tabular}

* 'Passive' = semiotic use ('passive' does not imply agentless behaviour in this context). 
In contrast to China's film industry, where commercially motivated production is dominated by organized professionals with access to capital, specialized equipment and state-controlled distribution networks, fashion involves much higher levels of distributed creativity and consumer engagement in productive processes. Consumers of fashion are encouraged to interpret, combine and apply the products and techniques of fashion professionals in the context of their own lives and aspirations. Success in the fashion game involves critical participation, rather than becoming a docile 'victim' of the latest trend. Experimentation and remixing, within the boundaries of 'taste', are admired.

Concepts of 'taste' are influenced not only by the fashion media, but also by a complex visual world that in twenty-first-century China includes newspapers, celebrity reporting (in magazines and online), film and television, as well as by the choices of friends, colleagues and associates. The role of honorific values and the absence of direct state intervention in this aspect of life are generating highly productive spaces within which individuals are encouraged to engage in creative consumption. In China, then, it might be argued that fashion is at the far end of a spectrum between state and consumer agency in creative and cultural production.

\section{COPYRIGHT AND THE BUSINESS OF CULTURE IN A DIGITAL AGE}

One of the things that makes the story of China's post-reform film, music and fashion industries so complex, and so interesting, is the growing tension between expanding international frameworks for the protection of intellectual property rights and new potential for the use and distribution of copyrighted works associated with transformative technological change. The tension between new technologies that facilitate dispersed copying, distribution and creativity and a desire to protect the rights of creators and promote investment and trade in creative products is not unique to China. However, in China a balance between protecting the rights of copyright owners and promoting the interests of society must be achieved in the context of very real development goals, as well as the challenges associated with the transition from a closed, centrally planned economic system towards a much more internationally integrated, market-driven model.

In the second half of the twentieth century 'core copyright industries' such as film and music were associated with a rhetoric that asserts that high levels of copyright protection are crucial to the existence of an economic contribution made by creative and cultural sectors of the economy (Boyle 2004). However, countervailing views about the benefits of intellectual property 
protection have long existed within the literatures of both law and economics. ${ }^{1}$ While international trades in cultural and intangible goods now form an increasingly valuable portion of the global economy, the concepts upon which copyright relies - 'creativity' and 'originality' - are difficult to transplant into new cultural, economic, artistic, social and technological contexts (Alford 1995; Mertha 2005; Liu 2006).

Significant costs are associated with the expansion of global intellectual property frameworks, particularly for developing countries that export few copyrighted products but require access to a great many in order to meet their development goals. At the same time, new technologies are helping to break down physical barriers previously associated with creation, distribution and use. In so doing, these technologies often encourage the use of content in ways that violate the rights of copyright owners. Given the costs associated with overly restrictive copyright protection for developing countries and the challenges for copyright associated with digital transformations, it is important to critically examine the extent to which copyright protection promotes creative innovation and growth in the creative industries.

In 2001 China signed the Agreement on Trade-Related Aspects of Intellectual Property Rights (TRIPs) - a requirement of World Trade Organization membership. The associated amendments to its copyright law have done a great deal to bring China into line with Organisation for Economic Co-operation and Development (OECD) copyright norms. In spite of this, levels of enforcement remain extremely low, and estimated rates of 'piracy' in film and music are as high as 90 per cent (Kennedy 2006). Although few figures are available on rates of trademark violation within China, it is widely accepted that the sale of 'fake' branded fashion items is also very common. China faces heavy pressure from foreign copyright owners and governments eager to expand markets for creative and cultural goods to better enforce its intellectual property laws. Nonetheless, creative and cultural businesses operating in China often have little choice but to adopt strategies that are not overly reliant on intellectual property enforcement.

The PRC's first copyright law did not come into existence until 1990. This was the beginning of a decade in which digital technologies, personal computers, mobile communication and the internet would transform cultural and communicative landscapes globally. The spread of new technologies for the copying, communication and use of content and very low levels of copyright enforcement have made it difficult for creative industries' business models that rely on an ability to control unauthorized copying and distribution of physical media to take hold in China. As a result many creative and cultural entrepreneurs have been prompted to explore new approaches to the value of creative products, and the ways in which their production might be financed and commercial returns generated. 
This book draws heavily on in-depth interviews with filmmakers, musicians and fashion designers, as well as entrepreneurs, lawyers, intellectual property court judges, and cultural officials conducted between 2003 and 2009. In the course of these interviews it became clear that many of China's film, music and fashion businesses are actively experimenting with strategies that allow them to function in a weak copyright environment and to operate commercially within limitations on content and industry structure set by the state. Both businesses and consumers are adapting to the regulatory environment in which they find themselves and finding ways to navigate highly complex landscapes of law, policy and commercial opportunity to maximum advantage.

While a large 'grey economy' exists around the distribution of unauthorized content, there is also growing awareness of the scalable value associated with intellectual property rights among Chinese creative industries professionals. At present, many of the businesses that are making money most successfully in the new environment are doing so by providing services, rather than as content owners. There is growing tension between groups that are developing new approaches based on services and advertising (particularly search engines) and businesses such as record labels, which continue to depend heavily on an ability to trade copyright. Copyright owners are beginning to pursue enforcement through the courts, and 'rent seeking' is by no means universally accepted as a legitimate way to make money.

According to Ronald Bettig (1996), copyright has the potential to act as a mechanism for converting creative works into instruments for the expression of capital 'much like real estate, bonds, stock, licenses, franchises, precious metals and so on' (Bettig 1996: 36). Political economists emphasize the expansionary logic of capital as a driving force in the formulation of intellectual property policies. As Bettig puts it:

when it comes to the domains of information and culture, the logic of capital drives an unending appropriation of whatever tangible forms of intellectual property and artistic creativity people may come up with, as long as this creativity can be embodied in tangible forms, claimed as intellectual property and brought to the marketplace. (Bettig 1996: 34)

Thus, it is to be expected that groups whose property entitlements and power over the market are increased by the expansion of intellectual property rights are strongly supportive of the copyright system. In markets where the copyright system is well established, record labels, publishers and vertically integrated film corporations frequently act as mediators between creative labourers and the market, coordinating the supply of new content and creative products with markets, providing the capital resources necessary for the physical production of creative works and making investments in promotion in 
order to stimulate demand. These coordinating firms depend heavily on the existence and enforceability of assignable intellectual property rights in order to define the products in which they invest and trade.

Nations in which the production and trade of copyrighted material make a significant contribution to the economy, such as the United States and the United Kingdom, have a similar vested interest in increasing international markets for their products through the construction of international frameworks for intellectual property protection capable of facilitating the international trade of copyrighted material. As commercially focused creative and cultural industries within China develop, commercial classes with an interest in protecting and expanding their entitlements are also forming. The growth of commercial classes with an interest in higher levels of copyright protection and enforcement may well serve as a vital element in the emergence of a stronger copyright regime in China. China's copyright authorities have recognized the significance of this group in the development of the nation's copyright system and are actively exploring ways to stimulate the growth of a copyright market. In 2009 the Copyright Protection Centre of China launched the world's first national copyright exchange: a live platform for trade in copyrighted works (China Daily 2009). Although the platform is still in its infancy, it is a deliberate effort to stimulate awareness of the commercial value of copyrights and to encourage investment in the creation of new works.

But larger questions remain about the extent to which the model of copyright protection posited in international frameworks such as TRIPs will benefit the growth of knowledge, the interests of society and, in the twenty-first century, the emergence of industries that take advantage of the communicative and collaborative potential of new technologies. As Bettig also observes, an ability to control the means of communication is central to the way in which 'capitalist classes' use copyright to extract value from artistic and intellectual labour in market-driven economies (Bettig 1996: 35). In China the state continues to maintain a high level of control over important distribution mechanisms, including print and broadcast media, as well as cinemas and mobile communication networks, and its efforts to control content available through the internet have been well documented. As a result, commercial classes have strong incentives for working within (and often around) the boundaries defined by the state.

The challenge for China's policymakers of harmonizing laws and regulations, establishing legal and administrative frameworks, negotiating the role of independent associations in representing the interests of specific groups, and cultivating a culture among entrepreneurs and regulators that supports intellectual property rights is formidable. It is unsurprising that it is taking time for legal frameworks intended to support highly specific models of market activity to supplant older systems of cultural sector management. Although China 
has formally adopted a copyright law that accords, broadly, with international standards for protection, it remains interested in controlling access to news and information by the public, and concerned with the impact of heterodox content on the social and political stability of the nation. New technologies and new ways of creating, using, distributing and monetizing content and culture are adding to the complexity of both limiting access to unauthorized content and ensuring that intellectual property laws are enforced. Regulators are struggling to keep pace with innovations being made by businesses, cultural producers and consumers.

In the case of film and music in China, both the business sector and the state have reasons for encouraging consumers back into centrally coordinated systems of distribution in China. However, users in China as in other markets are also motivated to actively seek out the content that they enjoy at the lowest possible price. Many creators who do not have access to official distribution channels are eager to share their work with others - either for fun, as part of a status or esteem system, or in the hope of financial gain. Increased access to physical technologies of copying, distribution and consumption of film and music and the growth of both peer-to-peer and grey-market distribution networks are challenging the state's ability to directly control what its citizens are able to access. They have also made it difficult for emerging commercial and entrepreneurial classes to use copyright to control the terms on which works might be distributed and used, prompting criticism of China's weak copyright environment, as well as experimentation with business models capable of functioning in the absence of controlled distribution.

\section{GOVERNMENTALITY}

China's policymakers remain keenly interested in popular culture and are developing methods of exerting their influence in the context of a marketdriven economy. The internet, publishing, print and broadcast media are all subject to policies aimed at preventing content deemed damaging to the interests of society or the state from being distributed.

Efforts to influence the moral, social and economic frameworks in which people function have taken on a prominent role in strategies for governing creative and cultural areas of production and consumption in the context of economic reform. Licences are required for film and television production, and official approval is needed if a film is to be screened in a legitimate cinema. Concerts and public performance are also controlled. Although China's policymakers are not able to remove unauthorized content from the media-sphere completely, they are able to restrict access to opportunities for the commercialization of any content that has not been approved by the authorities. 
In this context, Michel Foucault's insights into the processes involved in modifying the behaviour of a population help cast light on what the state is attempting to accomplish and why current developments are interesting. As Foucault observes, 'disciplining societies' involves more than the exercise of corporal power over individuals: locking people up if they break the law or placing them in a position where they have no choice but to comply with the will of the governing, for example removing all possibility of watching unauthorized content by ensuring that no unauthorized content is physically available. Rather, individuals' ability to choose whether to comply with the will of those who govern them is an essential element of any relationship of power. Foucault describes power as something that:

operates on the field of possibilities in which the behaviour of the active subjects is able to inscribe itself. It is a set of actions on possible actions; it incites, it induces, it seduces, it makes it easier or more difficult; it releases or contrives, makes more probable or less; in the extreme, it constrains or forbids absolutely, but it is always a way of acting upon one or more acting subjects by virtue of their acting or being capable of action. (Foucault 2002: 341)

\section{According to Foucault:}

What is to be understood by the disciplining of societies in Europe since the eighteenth century is not, of course, that the individuals who are part of them become more and more obedient, nor that all societies become like barracks, schools or prisons; rather, it is that an increasingly controlled, more rational, and economic process of adjustment has been sought between productive activities, communications networks, and the play of power relations. (Foucault 2002: 341)

This statement accurately describes what is now taking place in China, as efforts are made to encourage both consumers and producers to operate within the moral and political boundaries set by the state. Economic reforms, combined with technological developments, have made it harder to control access to unauthorized content. At the same time creative citizens and commercially focused cultural production are now seen as desirable. Private investment and innovation are required to ensure that controlled spaces are able to compete with unauthorized content for the attention of consumers. Encouraging entrepreneurial behaviour and commercially oriented cultural production within carefully delineated moral and political boundaries is thus playing an important role in disciplining China's post-reform creative industries.

In this book, I suggest that Foucault's concept of governmentality, which describes the role that individuals play in their own regulation and control through the internalization of standards of behaviour, is useful in understanding changes in the ways the state, individuals and commercial actors relate to 
and interact with creative and communicative works in China in the twentyfirst century. Governmentality allows us to consider how the relations that typified the socialist control state are being modified in the light of incremental reforms, moving cautiously towards the model that has been called 'authoritarian liberalism' (Jayasuriya 2001; Keane and Hemelryk Donald 2002).

Rather than focusing on the use of techniques of power and domination to control individuals, governmentality draws attention to the relationship between techniques of government and techniques of the self in shaping, guiding, modifying and correcting the ways in which individuals conduct themselves (Burchell 1996). Understood through this framework, intellectual property law, particularly copyright and trademark, represents an important point of contact between mechanisms of domination - the coercive power of formal law, and techniques of the self: self-regulation by both individuals and industries that rely on access to creative works, as well as the legally granted rights associated with creative works and identities.

Inevitably, intellectual property law also represents a point of intersection between the Chinese government's desire to exercise the power of the state within its own borders and its need to comply with the international frameworks of a global trading system. Dynamics of power between the state, firms and citizens include pressure on the Chinese government from foreign governments, as well as lobby groups acting on behalf of international copyright- and trademark-driven industries and commercial interests within China itself. It is well documented that US-based film and music industry lobbies have influenced the current international protection framework (Arup 2000; Wang 2003; Miller et al. 2005). Few commentators contest the proposition that the copyright law now in place in China reflects values and expectations established in the United States and Europe. While China's copyright legislation now accords with OECD norms, debates about the most appropriate levels of protection within any country continue. Scholars and activists from around the world have maintained their call for reform of the copyright system (Royal Society for the Arts 2005).

\section{THE ROLE OF LEGISLATION}

Since Mao's death, China's leaders have placed an increasing emphasis on the importance of formal law as a tool of government (Peerenboom 2002). However, as Seidman and Seidman (1994) observe, 'inevitably, people choose how to behave, not only in response to the law, but also to social, economic, political, physical and subjective factors arising in their own countries from custom, geography, history, technology and other, non-legal circumstances' (Seidman and Seidman 1994: 45). 
Legislative frameworks are just one factor in the complex landscape that consumers and businesses must navigate as they choose how to invest money, effort and time. It is thus inevitable that local circumstances, including distribution networks and social and political environments, will have a profound impact on perceptions and implementation of something as abstract as intellectual property rights. Social factors play an especially important role in markets for creative and cultural products, where 'value' and 'quality' are both subjective and contextual.

Capitalizing on social aspects of consumption by providing brand identities that can be co-opted by consumers is a well-established marketing strategy. A similar strategy can also be used to create negative associations around certain behaviours, for example campaigns intended to discourage consumers from purchasing 'pirated' films or music, or wearing 'fake' designer labels. Moral rhetoric is perhaps one of the most powerful tools in this kind of strategy. The Chinese government has been funding campaigns intended to establish a relationship between piracy and morality for a number of years (Wang 2003). In Beijing, for instance, it is now common to see television advertisements and billboards sporting slogans such as 'Be a responsible Beijinger; don't buy pirated films.' These campaigns are helping to build an image of copyright infringement as 'immoral': an important step in establishing it as a proscribed activity and employing 'techniques of the self' (Foucault 1988: 18-19) in controlling behaviour.

Employing moral rhetoric to mark out behaviour as not only illegal, but also immoral, is a well-recognized technique for maximizing the law's impact. As discussed earlier, the state's power over individuals involves much more than simply creating laws and punishing those who violate them. Imparting the values of the governing to the governed is a defining feature of 'hegemony': 'hegemony is a state within society whereby those who are dominated by others take on board the values and ideologies of those in power and accept them as their own' (Mills 2003: 75).

As Foucault points out, the successful government of others also depends on the capacity of the governed to govern themselves. If governments are to avoid the extremes of domination, they must aim to recruit the conduct of the governed - that is, to operate through a population's ability to regulate its own behaviour. Barry Hindess summarizes Foucault's position: 'successful government of others is often thought to depend on the ability of those others to govern themselves, and it must therefore aim to secure the conditions under which they are enabled to do so' (Hindess 1996: 105).

Encouraging the governed to govern themselves and ensuring that acting within the law is consistent with maximizing individual utility have important implications for the ways in which cultural production is managed in China. Ensuring that filmmakers and musicians accept the limits within which 
creativity and innovation are considered desirable by the state and convincing consumers that such limits are reasonable and compatible with satisfying cultural and entertainment experiences are more important than ever before in an era of dispersed productive capacities and distribution networks. The Chinese government's ability to enforce intellectual property law also raises important questions about its ability to control its own ranks - to limit corruption, to bring local officials into line and to ensure that centrally promulgated laws and policies are put into effect as is intended by the central government.

\section{ENTREPRENEURIAL GOVERNMENTALITY AND COPYRIGHT}

But, as I have already mentioned, there is more to this story than the exercise of state power over individuals. Efforts to integrate China into the international trading system, pressure by international actors on the Chinese government to build and implement a framework for the protection of intellectual property in the creative and cultural industries, and the Chinese government's own efforts to influence the behaviour of citizens are all important. However, the recognition of intellectual property rights associated with creative work and the growth of a highly competitive consumer landscape are prompting deeper shifts in the way that some groups in China think about creative works and activities. A market-driven economic system is creating opportunities for individuals to begin thinking about and acting upon creative and cultural products in an entrepreneurial manner.

Alexei Yurchak's extension of Foucault's concept of governmentality in relation to the activities of entrepreneurs is particularly helpful in understanding this process. According to Yurchak, writing about transitional economic activity in post-socialist Russia, to be an entrepreneur is to have an 'entrepreneurial governmentality', a disposition that allows entrepreneurs to understand economic and social relationships in terms of symbolic commodities such as risks, capital, profits, costs, needs and demands (Yurchak 2002). Russia and China are both making the transition from a centrally planned economy to one that is market driven. Many of the points raised by Yurchak about the challenges of building an entrepreneurial culture in a system that has not formally encouraged entrepreneurialism relate equally to China.

Yurchak explores the relationships between entrepreneurial activity and corruption in an environment where state-sanctioned channels have failed to meet the needs of consumers. Yurchak's concept of entrepreneurial governmentality helps to explain the changing ways in which creative producers and investors understand what they are making and how it might be used in China. In the case of film and music, the formal introduction of copyright law and 
market-driven reforms of the cultural sector are prompting individuals and groups involved in the production and distribution of film and music products to begin thinking about creative works as assets, which can be invested in, sold on and rented out, and which have the potential to generate profits.

An ability to understand economic and social relationships in terms of symbolic commodities such as risks, capital, profits, costs, needs and demands is not exclusive to creative industries professionals. As the fashion industry demonstrates, entrepreneurial governmentality is also the domain of consumers. Since Mao's death, Chinese consumers have become avid participants in the global fashion system: an area of consumption in which a consumer's investment of time, money and creative experimentation is part of a game that involves both risk and reward.

\section{FROM COPYRIGHT INDUSTRIES TO SOCIAL NETWORK MARKETS}

In markets such as the United States and Western Europe the film and recorded music industries developed during an analogue era, alongside an expanding system of intellectual property rights. In these markets copyright law often acts as a mechanism linking copyright owners with distributors and consumers and helping to coordinate a relationship between popularity and income for creators and investors. Commercial film and music businesses in China, on the other hand, are grappling with both a weak copyright system and the impact of digital technologies on their ability to control the copying and distribution of creative works. Ensuring that only authorized copies of a film or music product are distributed and that the copyright owner receives correct payment for each copy sold is all but impossible. In Bettig's terms, copyright owners are not able to control the communication infrastructure in China (Bettig 1996: 2).

Technology, rising disposable incomes and a liberal-market economy are combining to create new possibilities of thought and action for ordinary people, allowing them to adopt a much more active role in both the production and the consumption of creative and cultural works. The values that allow the fashion industry to function - a 'risk' culture, honorific values associated with the use of creative and cultural products rather than more passive processes of consumption, and the incorporation of creative and cultural products into processes of identity formation, self-expression, communication and play are quickly becoming evident in other areas of the creative and cultural industries.

In order to survive, film and music enterprises are being forced to understand what they have to sell in new terms, and to seek out new ways of making 
money, and new business models and strategies for expanding the regulated spaces in which they operate. The relationship between the state, commercial classes and consumers is being tested and negotiated. Creative and cultural industries must now satisfy the demands of the market in addition to those of the state. There is tension between businesses' desire for regulated space and the government's limited capacity (or will) to provide this.

According to Ruth Towse:

Creativity is central to the cultural or creative industries. It plays the equivalent role in these industries to that of innovation in other sectors of the economy. Just as firms in manufacturing have outlays on research and development (R\&D), so firms in the cultural industries search for new ideas and talented workers - artists - to create and supply them. (Towse 2001: 1-2)

New possibilities for interaction with creative and cultural products, digital technologies and instant communication are allowing users to become active participants in processes of production, distribution, creative experimentation and the selection of talent that were previously the domain of firms and commercially driven entrepreneurs. Amateur users and creators are being prompted to invest time and thought in choosing what and how to consume and actively seeking out skills, information and creative resources that allow them to derive maximum benefit from their consumption choices. It is also becoming possible for creativity to be sourced and coordinated among whole populations, rather than depending on more centralized processes of creation and distribution.

Invidious distinction (Veblen 1899), kudos, self-expression, social interaction and a desire for 'fun' are important drivers of investments of time, money, creative labour and risk among increasingly active 'consumers' in China and the rest of the world. Although established systems of production and market coordination still play an important role in China's emerging creative industries, entrepreneurial consumers are becoming central players in the generation of new creative knowledge and contributing to change and growth in the economy in important ways. As Potts (2003) observes, entrepreneurialism, knowledge and the democracy of economic agents are three driving forces of economic growth:

Competitive or entrepreneurial actions create new knowledge and/or destroy old knowledge, and the market - the democracy of economic agents - decides whether or not it is a good idea. People are motivated by private gain, but if they succeed, then it becomes a public gain: an old problem is better solved, or a new problem is solved. This is what entrepreneurs do, and it is why they are central to the health of an economic society. Entrepreneurs drive economic evolution, and thereby, if harnessed, economic growth. (Potts 2003: 4) 
An increasingly open and dynamic commercial and cultural environment in China is giving rise to new opportunities to explore and express identity and values through clothing, entertainment, hobbies, food and experiences, particularly in urban settings. Many Chinese consumers are now eagerly seeking out the literacies and skills necessary to navigate complex media, commercial, social and cultural landscapes. The desire for information about how to live, how to consume, what brands and symbols represent and which purchasing choices or investments of time and effort will provide the greatest rewards in the specific context that an individual inhabits is creating new markets for information.

In the face of so much choice, social network markets (Potts et al. 2008) are coming to the fore. Social network markets allow individuals to take advantage of the tastes and intelligence of friends and associates and, with the help of information networks such as the media, to glean information from the decisions of consumers in other cities or countries. Recommendations from trusted others allow individuals to minimize the risks of their own purchases and can serve to integrate an individual more firmly within a peer group. Social networks are also more dynamic than many other sources of information, and capable of providing up-to-date knowledge that accurately reflects access options available to users, regardless of whether they are legal or illegal, or part of the free economy, the grey economy or a formalized economic system.

It is arguable that, in actively seeking out creative products and information from the widest possible range of sources, both legal and illegal, and exploring new ways to interact with creative content, Chinese consumers are acting as catalysts in processes of creative evolution. Their participation in markets for creative and cultural products is a form of transformative engagement, which has an impact on both the form of creative products and the organization of the productive processes and business models that supply them. In Beinhocker's (2006) terms, their activities both feed and shape the evolutionary dynamics of knowledge growth and wealth creation. Active consumers are a powerful source of creative energy and population-wide experimentation involved in product innovation, and are shaping the markets within which physical technologies, business models and regulatory frameworks must function.

While governments and sectors of the established copyright industries attempt to regulate consumer behaviour through the use of moral rhetoric and formal law, individuals are actively developing and applying their own knowledge of technical possibility and practical boundaries to their daily lives. Users are exploiting available resources to take control of distribution processes, ignoring formal legal restrictions relating to reuse of content and developing and applying their own creative and cultural codes to their actions. More and 
more, the lived reality for many Chinese citizens involves cultural and creative curiosity, expressed as a desire for new experiences and new products, as well as a desire to play and create.

The internet and other communication and copying technologies are disruptive technologies precisely because they have superseded networks of production and distribution previously dominated by either governments or established corporate elites. The difficulties associated with applying business models based around linear value chains of professional production of creative works, controlled distribution and limited possibilities for use in China are allowing new modes of creative production and interaction to evolve. Business models in China are also evolving as firms adapt to the environment in which they must operate and compete to win the attention of ever more worldly, demanding, fashion-conscious consumers.

Copyright law represents a point of intersection between the coercive power of formal law and self-regulation by individuals and copyright industries. However, the spaces that now exist between formal regulation and possibilities of action are, arguably, producing the highest levels of innovation in both the uses of creative works and the generation of new business models. Low levels of copyright enforcement, access to new technologies and an enviable range of content are allowing both consumers and creative entrepreneurs to begin thinking about creative works in new ways. Content is being understood as something that can be chosen, enjoyed on a range of platforms, manipulated, compiled, given to friends and used as a fashion item or social accessory. Rather than something that professionals make and distribute for non-professionals to consume, content is becoming something that can be made, distributed and remixed by anyone. Both creative and cultural industry professionals and users are beginning to understand the value of content in terms of its social functions, the services and accessories that allow it to be delivered with the highest levels of convenience or novelty and its potential as a resource for reuse, remixing and re-creation.

The gaps between formal law and practical reality are prompting businesses to explore new approaches to capturing the commercial value of creative works. However, they are also allowing consumers to explore new ways of using and interacting. It is conceivable that, rather than making the transition towards better enforcement of copyright law and the emergence of copyrightdriven creative and cultural industries, new approaches to the role of value in the creative industries may be emerging in China. China's emerging commercial classes are beginning to understand creativity and content in terms of their value as intellectual property. But they are also becoming aware of the attention economy, the power of social network markets and the possibility of charging for services, such as advertising or the delivery of content to mobile devices, rather than for the content itself. The future of business models based 
on the ownership and controlled distribution of expert-generated copyrighted material is far from assured.

\section{CHAPTER OUTLINE}

As mentioned earlier, in order to better understand this process of evolution away from government by the state in China, towards creative and cultural industries in which entrepreneurial consumers are driving forces, this book explores the development of three very different creative industries: film, music and fashion. These three industries are examined through the lens of changing approaches to governance in China's cultural sector, as well as the role that intellectual property is playing in both this transformation and the growth of China's creative industries. The film, music and fashion industries all rely heavily on creative professionals who apply their skills and talents to developing products that are sold in highly competitive markets. However, as this book explores, there are also important differences between the ways in which the power of the state is being exercised in relation to these industries in China, and in the role of intellectual property in their growth and development.

Chapter 2 explores China's integration into a global system of intellectual property rights and critically examines arguments that high levels of 'piracy' in China are a result of a clash between foreign approaches to protecting intellectual property and Chinese attitudes to creativity and copying. The chapter also further explains how the concepts of discourse, governmentality and entrepreneurial governmentality might help to shed light on debates about intellectual property protection in China and the Chinese government's approach to its implementation. Finally, Chapter 2 highlights the difficulties inherent in widely accepted definitions of the creative industries, which emphasize intellectual property, and attempts to understand and promote growth of this sector of the economy in developing nations.

Chapter 3 focuses in on China's film industry. A growing proportion of China's population now has access to cameras, personal computers and broadband internet connections. Technology is making it possible for more people than ever before to engage in what $\mathrm{Xu}$ (2007) calls 'cinematic modes of production'. However, the commercially oriented film industry continues to depend heavily on access to coordinated mass distribution channels, as well as the relatively high levels of capital, specialist skills and equipment required for the production of feature films. The commercial film industry's dependence on access to high levels of investment and a coordinated cinema distribution system have made it possible for the Chinese government to maintain a high level of control over this area of production, in spite of the fact that new technologies have made controlling the public's ability to access content difficult. 
Chapter 4 considers the situation in the music industry, where the state's power is being exercised less directly than in the case of film. Although some groups estimate that up to 90 per cent of physical music products are 'pirated' (Kennedy 2006) and copyright enforcement online is a major challenge, rapid mobile uptake has been associated with the growth of a lucrative market in mobile music, which is quickly becoming China's most significant source of music-related revenue (Yao 2007). But, while commercial interests, private investment and consumer taste are playing a vital role in the formation of an entirely new market for music products sold directly to mobile devices, China's government remains a dominant stakeholder in the nation's mobile communication networks.

In Chapter 5 it becomes clear that the state is playing an entirely different role in the growth of China's fashion industry. Since the very earliest days of reform and opening up, fashion has been associated with a level of creative freedom absent in many other areas of cultural production in China. The fashion system's dependence on social networks and consumer engagement in order to function has made fashion particularly resistant to attempts to directly influence what people wear. The government's focus in the post-reform era appears to have been on creating an environment conducive to the growth of a market for the products of an industrialized fashion system, rather than on attempting to directly control what is designed and worn. This approach, which has coincided with market-oriented reforms of magazines and the growth of an advertising industry, seems to be working particularly well in China. Consumer demand for genuine versions of branded products appears to be countering the availability of 'fake' products, and China's fashion industry is developing quickly.

Chapter 6 considers the troubled relationship between economic approaches to the creative industries and intellectual property theory. Written with evolutionary economist Jason Potts, this chapter argues that much of the confusion about intellectual property's role in the creative industries results from overlooking three important aspects of the relationship between IP and the growth of knowledge. These are: 1) the effect of globalization; 2) the value of monopoly incentives to create input, compared to the value of reusing creative output; and 3) the evolution of business models in response to institutional change. We argue that the evolutionary dynamics of these three factors suggest that a substantial weakening of intellectual property will, in theory, produce positive net public and private benefit.

Finally, Chapter 7 considers important areas of research yet to be explored in relation to both the growth of the creative industries in China and the role of intellectual property law in the creative industries more widely. Given the significance of the creative industries to the strength of the global economy, and their potential to help developing nations shift away from their dependence on 
low-cost manufacturing toward higher-value-added areas of creative production, understanding the mechanisms for their growth may provide important clues about the regulatory frameworks and policy approaches likely to help them succeed.

Overall, the book shows that social network markets and consumer creativity and entrepreneurship are powerful forces in the production and commercialization of cultural commodities in the twenty-first century. As the case studies explored in the book demonstrate, entrepreneurial consumers with access to content from a diverse range of sources are helping to drive both creative and commercial developments in China. Although copyright is playing a role in the creative economy that is emerging, China's experience demonstrates that intellectual property protection is not a prerequisite for the growth of the creative industries. Rather, it is just one factor in the dynamic co-evolution of physical technologies, social technologies and business models. Thus new approaches to understanding the economic relationship between intellectual property protection and the creative industries, which recognize the dynamic nature of business models and the productive and entrepreneurial value of creative consumers, are needed.

\section{NOTE}

1. An excellent discussion of this history can be found in Deazley (2006). 